\title{
Palliative Care and Interstitial Lung Disease
}

DOI:

10.1097/SPC. 0000000000000285

\section{Document Version}

Accepted author manuscript

Link to publication record in Manchester Research Explorer

\section{Citation for published version (APA):}

Bajwah, S., \& Yorke, J. (2017). Palliative Care and Interstitial Lung Disease. Current Opinion in Supportive and Palliative Care, 11(3), 141-146. https://doi.org/10.1097/SPC.0000000000000285

\section{Published in:}

Current Opinion in Supportive and Palliative Care

\section{Citing this paper}

Please note that where the full-text provided on Manchester Research Explorer is the Author Accepted Manuscript or Proof version this may differ from the final Published version. If citing, it is advised that you check and use the publisher's definitive version.

\section{General rights}

Copyright and moral rights for the publications made accessible in the Research Explorer are retained by the authors and/or other copyright owners and it is a condition of accessing publications that users recognise and abide by the legal requirements associated with these rights.

\section{Takedown policy}

If you believe that this document breaches copyright please refer to the University of Manchester's Takedown Procedures [http://man.ac.uk/04Y6Bo] or contact uml.scholarlycommunications@manchester.ac.uk providing relevant details, so we can investigate your claim.

\section{open 2 Access}




\title{
Palliative Care and Interstitial Lung Disease
}

\section{Sabrina Bajwah and Janelle Yorke}

Corresponding author:

Dr Sabrina Bajwah

Cicely Saunders Institute

King's College London

Bessemer Rd

SE5 9PJ

$\mathrm{T}:+44(0) 2078485826$

sabrina.bajwah@kcl.ac.uk

\begin{abstract}
Purpose of review: describe why this review is timely and relevant.

The palliative care needs of people with Interstitial Lung Disease (ILD) have recently been highlighted by the National Institute for Health and Care Excellence. All people with progressive ILD should receive best supportive care to improve symptom control and quality of life and where possible this should be evidence based.
\end{abstract}

Recent findings: describe the main themes in the literature covered by the article.

Deaths from ILD are increasing and deaths in hospital are more common compared to home. People with ILD experience a wide range of symptoms including breathlessness and cough. People living with ILD often suffer unmet physical and psychological needs throughout the disease journey. Few appropriately validated outcome measures exist for ILD which has hampered research on the longitudinal experience of symptoms and quality of life and the evaluation of interventions. Recent recommendations from the National Institute of Clinical Excellence promote the use of a new palliative care needs assessment tool. Use of a tool in busy respiratory clinics may help to highlight those requiring specialist input.

\section{Summary: describe the implications of the findings for clinical practice or research}

Further research into the role of opioids, oxygen and neuromodulatory agents in symptom management are needed. In addition, exploration of breathlessness and case conference interventions in transitioning patients from the hospital to community settings is a priority. Further work is needed to identify a core set of validated ILD-specific patient-reported outcome measures for the robust evaluation of interventions.

\section{Key words}

Interstitial lung disease, palliative care, symptoms.

\section{Key points}

- Deaths from ILD are increasing and deaths in hospital are more common than home.

- Patients and carers often suffer unmet physical and psychological needs and recent recommendations from the National Institute of Clinical Excellence promote the use of a new palliative care needs assessment tool.

- Further research into symptom management, complex interventions transitioning patients from the hospital to community settings and ILD patient-reported outcome measures is needed. 


\section{Introduction}

The palliative care needs of people with Interstitial Lung Disease (ILD) have recently been highlighted by the National Institute for Health and Care Excellence (NICE)(1). This review aims to present the most up to date evidence for the epidemiology and management of the main symptoms of ILD. In addition, we will highlight psychological needs (including impact on carers) and suggest future areas for research.

\section{Background}

ILD refers to a group of conditions affecting the interstitium of the lung, all of which share the common characteristics of lung scarring (2). If a significant proportion of the lung becomes scarred, respiratory failure can occur (3). The main ILD diseases that are fibrotic (resulting in scarring) and progressive in nature are Idiopathic Pulmonary Fibrosis (IPF) and NonSpecific Interstitial Pneumonia (NSIP). For the purposes of this paper, these diseases will be collectively referred to as Progressive Idiopathic Fibrotic Interstitial Lung Disease (PIF-ILD).

There are at least 5,000 new cases of PIF-ILD each year in England and Wales, with a similar number of deaths (4). This means that in the UK, more people will die each year from PIF-ILD than from ovarian cancer, lymphoma, leukaemia, mesothelioma or renal cancer (4).

At present there are approximately 15,000 people in the UK with a PIF-ILD diagnosis (4). People living with PIF-ILD experience a progressive loss of functional ability and ultimately, die from acute respiratory failure. Median survival from diagnosis is approximately 3 years $(5,6)$. PIF-ILD is predominately a disease of later life, with two-thirds of people being over 60 years old at presentation (7) with survival being poorest in those diagnosed later in life. This demographic profile is important as the incidence is set to double by 2030 as populations age (8). UK data suggests that the estimated financial burden of hospitalisation for PIF-ILD in 2010 was $£ 16.2$ million (9) with recent data from the United States study showing the mean cost of a non-transplant admission as $\$ 16,000$ (10). Importantly, a 2017 study linked 
14 years of English death registration data showing that ILD related mortality is increasing (9.2\% annually) (11). Seventy percent of those living with ILD died in hospital with comorbidities, social deprivation and living in urban areas independently increased the chances of death in hospital(11).

For the current review, multiple PubMed searches were conducted using combinations of search terms (ILD/IPF, dyspnea/dyspnoea/breathlessness, cough, fatigue, palliative care/end of life, quality of life, surveys/questionnaires/psychometrics/patient reported outcome) plus names and acronyms of various instruments for quality of life and symptoms (for example K-BILD and Dyspnoea-12). Choices of which measures to include in this review were based on considerations such as ease of use, responsiveness, relevance across diagnoses, and availability of published data on use in palliative care.

\section{Respiratory Symptoms in ILD}

Those affected by PIF-ILD have limited treatment options and in the terminal stages, the focus of care is on palliation of symptoms. A 2017 systematic review to determine the symptom prevalence in those living with PIF-ILD found the overwhelming majority had breathlessness and cough (12). In addition a wide array of other symptoms which include insomnia, gastrooesophageal reflux and depression were experienced (12).

\section{Breathlessness}

A number of factors are thought to contribute to breathlessness in PIF-ILD. These include ventilator restriction, impaired gas exchange, impaired functional status, depression and comorbidities (eg emphysema, pulmonary hypertension, obesity) (13). Breathlessness is not only a common symptom, but may precede diagnosis by 6.8 months to 4 years (14). 
Breathlessness in IPF shows a strong correlation with quality of life (15) and mortality (16). People living with ILD may describe their breathlessness as fatigue (17) and it is important to distinguish between these two symptoms. People living with chronic lung disease report higher levels of fatigue when they are breathlessness and have a more negative mood state $(18,19)$.

\section{Management of breathlessness}

Breathlessness is often multi-factorial and assessment should involve detailed history taking comprising physical, psychological and social domains (20). Any reversible/treatable cause such as infection or pulmonary hypertension should be managed appropriately.

\section{Non-pharmacological interventions}

A Cochrane review looking at non-pharmacological interventions for breathlessness in advanced stages of malignant and non-malignant diseases (21) found no studies containing people with ILD. However, as there may be a close link between psychosocial issues and breathlessness, psychosocial interventions (21) such as counseling, cognitive behavioural therapy and psychotherapy may be useful. A 2012 systematic review looking at interventions to improve symptoms and quality of life in people living with PIF-ILD examined 194 participants receiving pulmonary rehabilitation and found there was mixed evidence in IPF that pulmonary rehabilitation improves shortness of breath but positive effects were seen on fatigue and quality of life (22). A subsequent Cochrane review in 2014 (23) found that immediately following pulmonary rehabilitation, participants could walk further and reported less breathlessness and improved quality of life. Information was insufficient to establish whether ongoing effects were noted once pulmonary rehabilitation had stopped. On balance, pulmonary rehabilitations may help with the symptom of fatigue (22) which has been reported in up to $97 \%$ of people living with IPF (24) and is a major problem affecting their quality of life (19). Those with advanced disease can benefit if they are selected 
appropriately and if realistic goals are set (25). Interestingly, other complex interventions such as breathlessness intervention services may also be beneficial; Higginson et al (26) conducted a randomised controlled trial of 105 people living with refractory breathlessness which included nineteen people living with ILD. They found that people who received the integrated palliative care and respiratory breathlessness support service had significantly improved breathlessness mastery, a domain of the Chronic Respiratory Disease Questionnaire. Mastery assessed subjective control over breathlessness and effects on Qol and function, and was on average $16 \%$ higher for those receiving the breathlessness support service. This requires further research but the results are encouraging.

\section{Pharmacological}

In 2012 Bajwah et al (22) they found only one small study $(n=11)$ using diamorphine which showed improvement of breathlessness following administration of diamorphine. In addition, the recent Cochrane review for the use of opioids for breathlessness at the end of life (27) found no conclusive evidence for the use of opioids for ILD. However, this only included one study for ILD ( $\mathrm{n}=6)$ (28) which looked at nebulised morphine. A recent 2016 systematic review (29) aimed to clarify the role of opioids in the treatment of breathlessness in people living with IPF. A paucity of IPF studies were found and studies were primarily conducted in COPD. An Australian pharmacovigilance study conducted in 2011 (30) trialed morphine sulphate in a group of palliative patients which included 10 people with ILD and showed promising results. A follow up randomised study looking at the use of modified release morphine in ILD is due for publication in late 2017. (ANZCTN Trial registration number: ACTRN12611000711910)

A 2010 Cochrane review $(31,32)$ to determine the effect of oxygen therapy on survival and quality of life in ILD found no randomised controlled trial reporting quality of life measures. A subsequent 2013 double blind randomised controlled trial (33) aiming to assess the effect of ambulatory oxygen on dyspnoea in 20 IPF patients without resting hypoxemia found no 
significant difference in dyspnoea between ambulatory oxygen or air at each time point. Further detailed research looking at the role of oxygen in symptom control of these patients is needed.

\section{$\underline{\text { Cough }}$}

Cough is a common problem in IPF with $60-88 \%$ reporting it as a symptom $(24,34,35)$. Cough frequency is high in PIF-ILD with median (range) 24 hour cough counts varying from $226(36-946)$ to $520(117-1493)(36,37)$. Cough impacts on every part of the lives of those living with ILD. Cough leads to relationship difficulties, avoidance of public areas and emotional challenges (15). Women with cough are often troubled by stress incontinence (38). A French study in a mixed group of 28 people living with ILD which included IPF patients, showed that stress incontinence was present in $50 \%$ of females with chronic cough compared to $7 \%$ of healthy controls (39). All were ashamed of the symptom and $79 \%$ felt unable to mention it to their physician (39).

\section{Management of cough}

Cough on eating, postprandially or on phonation may indicate reflux (38). Proton Pump Inhibitors (PPI) are the treatment of choice for gastro-oesophageal reflux disease (GORD) related chronic cough and improves GORD related cough in $36-100 \%$ of patients $(40-42)$. In addition, $\mathrm{H} 2$ antagonists have also been shown to improve GORD cough (43). However, full acid suppression may only be possible by twice daily PPI and nocturnal H2 antagonist (44). A prokinetic agent such as metoclopramide should be added if a diagnosis of oesophageal dysfunction is suspected (45).

In addition, it has been proposed that there may be increased cough reflex sensitivity in ILD with an upregulation of sensory fibres in the lung (46). Recent studies have highlighted the effectiveness of neuromodulatory agents such as thalidomide and gabapentin. A double 
blind crossover randomised controlled trial in 98 IPF patients conducted by Horton et al (47) showed promising results of thalidomide in improving cough and quality of life. However, concerns with regards to side effects and storage issues may make this a difficult drug to prescribe in everyday practice. Exciting evidence has emerged on the effectiveness of gabapentin in managing cough in healthy volunteers (48) and studies are needed to investigate whether this may be an effective and viable treatment option in ILD.

\section{Impact of ILD on patient and carer}

Recent years has seen a welcomed increase in the number of published papers presenting qualitative methods that aim to provide an in-depth understanding of the experience of living with IPF. As such, this section will provide a summary of studies relating to the experiences of IPF patients and carers, and does not include studies of other types of ILD.

The current qualitative literature tends to explore the experience of living with IPF from the perspective of both the patient and carer. With this approach the patient and carer are interviewed together ('dyads') and can provide unique insights into the wider impact of IPF. Three contemporary themes emerge from the qualitative literature: overwhelming symptom burden, perceptions of palliative care, and information needs.

Lindell et al (49) analysed focus group data and reported that symptoms present an overwhelming burden for both patient and carer, reinforcing that found in previous in depth qualitative work(15). Coughing in particular was reported to be 'draining' for those living with IPF and led to carer sleep deprivation (49); and described in terms of 'overwhelming coughing attacks'(50). Overgaard et al (50) identified a 'gradual and tacit role shift' when breathlessness impacted on the chores that the person with IPF once completed. Breathlessness and commencing long-term oxygen is viewed by patient and carer as a sign of deterioration, and although oxygen is first experienced as a limitation, it comes to be 
viewed as a necessity (50). Both patients and carers become acutely aware of symptoms and their progression (50).

Early introduction of palliative care is advocated in IPF as a means to reduce symptom burden (51). However, Lindell et al (51) and Bajwah et al (52) found that those living with IPF can be reluctant to engage with palliative care services and discussions about advance care planning. It was noted that there was some confusion among focus group attendees about the goals of palliative care and how this option differed from hospice (49). Sampson et al (53) interviewed 27 patients and 21 paired carers and found that interviewees frequently compared their situation unfavourably with cancer patients who were deemed to have "help coming from every direction". Palliative care was viewed as "that path to death"; although two recipients of palliative care reported significant improvements on quality of life (53). A needs assessment tool for specialist palliative care in ILD has recently been validated (54, 55) and endorsed by the National Institute for Health and Clinical Excellence (E0070), which may help to address such issues.

The need for accessible and up-to-date information for those living with ILD is consistently reported in recent studies $(49,50,53,56,57)$. Specific information needs that need to be addressed include, pharmacological therapies and managing associated side-effects (57), disease trajectory $(53)$, approaches to and goals of palliative care $(49,53)$ and support for family members (53).

The transition from specialist care to community care has been addressed by Bajwah et al (52) who found that a community case conference intervention improved communication between the specialist centre, community health professionals and those living with ILD.

Validated tools to measure symptoms in ILD

Patient-reported outcome measures (PROMs) attempt to capture the patient's view about symptom experiences and impact, activity limitation and health-related quality of life (HRQL). 
Given the frequency and severity of distressing symptoms and reduced HRQL in those living with IPF, there is a relative paucity of IPF-specific tools.

Dyspnoea measures fall into two categories: direct measurements (for example the Borg scale, visual analogue scale (VAS), Numerical Rating Scale (NRS), and Dyspnoea-12). (5860) and indirect measures that reflect activity limitation related to dyspnoea (for example the MRC dyspnoea scale and University of California San Diego Shortness of Breath Questionnaire (UCSD)) $(61,62)$ The NRS (59) consist of a single item scale that measures breathlessness severity or distress by asking the patient to mark or point to the number reflecting their shortness of breath. Given their relative ease of completion and not necessarily being linked to an activity, the NRS is useful in the palliative care setting.

The Dyspnoea-12 was developed using patients with a range cardiopulmonary conditions ( $n=358)$ including ILD $(n=129)(60)$. It consists of 12 items that represent sensory-perceptual and affective distress domains of breathlessness. The time frame for items is 'these days,' rather than a specific interval or activity which may be a useful timeframe in a palliative care context. Dyspnoea-12 has demonstrated excellent reliability and validity in ILD ( $n=101$; including IPF $\mathrm{n}=67$ ) (63). The MRC scale is used extensively to categorise patients according to dyspnoea related activity limitation (60) and has been demonstrated to be predictive of disease progression in IPF (64). The most frequently used and well-validated tool for use in IPF is the UCSD, a 24-item measure that assesses self-reported shortness of breath while performing a variety of activities of daily living (62). The UCSD has been used as a secondary endpoint in IPF trials and data are emerging to confirm its reliability and validity in IPF, including its ability to assess change in dyspnoea over time $(65,66)$.

Few measures for the assessment of cough are available and data on the validity in IPF is poor. Cough-related quality of life measures include the Leicester Cough Questionnaire (LCQ) (67) and the Cough Quality of Life Questionnaire (CQLQ) (68). The VAS is frequently used to assess chronic cough including cough severity and impact. Limited studies in IPF 
show that both the VAS and LCQ demonstrate acceptable correlation with objective cough counts (46); but no other reliability and validity data are available.

Currently, only one IPF-specific HRQL tool is available - A Tool to Assess Quality of Life in IPF (ATAQ) (69). The original ATAQ version consisted of 89 questions, but a modified version consisting of 43 items has been developed based on pooled data from the United States and United Kingdom (70). Further longitudinal studies are needed to confirm the sensitivity of ATAQ to changes in a patient's health status and in response to treatments. The King's Brief Interstitial Lung Disease (K-BILD) was developed in a mixed population of People with ILD including 49 with IPF (71). It is a short questionnaire consisting of 15 items in three domains (breathlessness and activities, chest symptoms, and psychological). Further research is needed to assess how the tool performs in IPF and within a palliative care context.

Originally developed in COPD, the St George's Respiratory Questionnaire (SGRQ) (72) is commonly used in studies involving patients with IPF (73). A recent assessment of the psychometric properties of the SGRQ in a cohort of patients with IPF $(n=428)$ demonstrated the acceptability of its reliability, construct validity and responsiveness in IPF(74). The original SGRQ has been adapted for use in IPF - the SGRQ-I (75). However, further evidence of the validity of the SGRQ-I for use as a specific-IPF measure is needed, including the context of palliative care.

\section{Areas for future research}

Further work is needed to clarify the role of oxygen, opioids and neuromodulatory agents in the symptom management of those living with ILD. In addition, further investigation into the role of breathlessness intervention services and the case conference in providing integrated and individualised care at the end of life is needed. Further work is needed to identify core PROMs specific to ILD/IPF to enable robust evaluation of interventions. 


\section{Conclusion}

This review summarises the current literature for symptomatology in ILD focusing on symptom measurement and interventions for symptom management. Despite a welcomed increase in the number of recently published studies this area of research remains in its infancy. It is hoped that this review will help to guide future ILD research.

\section{Acknowledgements}

None

Financial support and sponsorship

None

Conflicts of interest.

None 


\section{References}

1. Excellence NIfC. Quality standard for idiopathic pulmonary fibrosis DRAFT. In: NICE, editor. Manchester: NICE; 2014.

2. Strieter RM. Mechanisms of pulmonary fibrosis: conference summary. Chest. 2001;120(1 Suppl):77S-85S.

3. Du Bois RM. Strategies for treating idiopathic pulmonary fibrosis. Nature Reviews Drug Discovery. 2010;9 (2):129-40.

4. Navaratnam V, Fleming KM, West J, Smith CJ, Jenkins RG, Fogarty A, et al. The rising incidence of idiopathic pulmonary fibrosis in the U.K. Thorax. 2011;66(6):462-7.

5. Hubbard R, Johnston I, Britton J. Survival in patients with cryptogenic fibrosing alveolitis: a population-based cohort study. Chest. 1998;113(2):396-400.

6. Hubbard R, Venn A. The impact of coexisting connective tissue disease on survival in patients with fibrosing alveolitis. Rheumatology(Oxford). 2002;41(6):676-9.

7. Kim DS, Collard HR, King TE, Jr. Classification and natural history of the idiopathic interstitial pneumonias. Proc Am Thorac Soc. 2006;3(4):285-92.

8. Fernandez Perez ER, Daniels CE, Schroeder DR, St Sauver J, Hartman TE, Bartholmai BJ, et al. Incidence, prevalence, and clinical course of idiopathic pulmonary fibrosis: a population-based study. Chest. 2010;137(1):129-37.

9. Navaratnam V, Fogarty AW, Glendening R, McKeever T, Hubbard RB. The increasing secondary care burden of idiopathic pulmonary fibrosis: hospital admission trends in England from 1998 to 2010. Chest. 2013;143(4):1078-84.

10. Mooney JJ, Raimundo K, Chang E, Broder MS. Hospital cost and length of stay in idiopathic pulmonary fibrosis. Journal of Medical Economics. 2017:1-7.

11. Higginson IJ, Reilly CC, Bajwah S, Maddocks M, Costantini M, Gao W, et al. Which patients with advanced respiratory disease die in hospital? A 14-year population-based study of trends and associated factors. BMC medicine. 2017;15(1):19.

12. Carvajalino S, Reigada C, Johnson M, Dzingina M, Bajwah S. Symptom Prevalence of Patients with Fibrotic Interstitial Lung Disease: A Systematic Literature Review Unpublished. 2017.

13. Ryerson CJ, Collard HR, Pantilat SZ. Management of dyspnea in interstitial lung disease. Curr Opin Support Palliat Care. 2010;4(2):69-75.

14. Alhamad EH, Masood M, Shaik SA, Arafah M. Clinical and functional outcomes in Middle Eastern patients with idiopathic pulmonary fibrosis. Clin Respir J. 2008;2(4):220-6.

15. Bajwah S, Higginson IJ, Ross JR, Wells AU, Birring SS, Riley J, et al. The palliative care needs for fibrotic interstitial lung disease: a qualitative study of patients, informal caregivers and health professionals. Palliat Med. 2013;27(9):869-76.

16. King TE, Jr., Schwarz MI, Brown K, Tooze JA, Colby TV, Waldron JA, Jr., et al. Idiopathic pulmonary fibrosis: relationship between histopathologic features and mortality. Am J Respir Crit Care Med. 2001;164(6):1025-32.

17. Janson-Bjerklie S, Carrieri VK, Hudes M. The sensations of pulmonary dyspnea. Nurs Res. 1986;35(3):154-9.

18. Oh EG, Kim CJ, Lee WH, Kim SS. Correlates of fatigue in Koreans with chronic lung disease. Heart Lung. 2004;33(1):13-20.

19. De Vries J, Kessels BL, Drent M. Quality of life of idiopathic pulmonary fibrosis patients. European Respiratory Journal. 2001;17(5):954-61.

20. Thomas S, Bausewein C, Higginson I, Booth S. Breathlessness in cancer patients Implications, management and challenges. Eur J Oncol Nurs. 2011.

21. Bausewein C, Booth S, Gysels M, Higginson I. Non-pharmacological interventions for breathlessness in advanced stages of malignant and non-malignant diseases. Cochrane Database Syst Rev. 2008(2):CD005623. 
22. Bajwah S, Ross JR, Peacock JL, Higginson IJ, Wells AU, Patel AS, et al. Interventions to improve symptoms and quality of life of patients with fibrotic interstitial lung disease: a systematic review of the literature. Thorax. 2012.

23. Dowman L, Hill CJ, Holland AE. Pulmonary rehabilitation for interstitial lung disease. The Cochrane Library. 2014.

24. Vallejo SL, Sahn SA, Ford DW. Perception of illness in idiopathic pulmonary fibrosis: A prospective survey of patients and their family members. Chest. 2007;132(4):582S-S.

25. Ries AL, Bauldoff GS, Carlin BW, Casaburi R, Emery CF, Mahler DA, et al. Pulmonary Rehabilitation: Joint ACCP/AACVPR Evidence-Based Clinical Practice Guidelines. Chest. 2007;131(5 Suppl):4S-42S.

26. Higginson IJ, Bausewein C, Reilly CC, Gao W, Gysels M, Dzingina M, et al. An integrated palliative and respiratory care service for patients with advanced disease and refractory breathlessness: a randomised controlled trial. The Lancet Respiratory Medicine. 2014.

27. Barnes H, McDonald J, Smallwood N, Manser R. Opioids for the palliation of refractory breathlessness in adults with advanced disease and terminal illness. The Cochrane Library. 2016.

28. Harris-Eze A, Sridhar G, Clemens R, Zintel T, Gallagher C, Marciniuk D. Low-dose nebulized morphine does not improve exercise in interstitial lung disease. American journal of respiratory and critical care medicine. 1995;152(6):1940-5.

29. Kohberg C, Andersen CU, Bendstrup E. Opioids: an unexplored option for treatment of dyspnea in IPF. European clinical respiratory journal. 2016;3.

30. Currow DC, McDonald C, Oaten S, Kenny B, Allcroft P, Frith P, et al. Once-daily opioids for chronic dyspnea: a dose increment and pharmacovigilance study. J Pain Symptom Manag. 2011;42(3):388-99.

31. Crockett A, Cranston JM, Antic N. Domiciliary oxygen for interstitial lung disease. The Cochrane Library. 2001.

32. Zieliński J. Long-term oxygen therapy in conditions other than chronic obstructive pulmonary disease. Respiratory care. 2000;45(2):172-6; discussion 6-7.

33. Nishiyama O, Miyajima H, Fukai Y, Yamazaki R, Satoh R, Yamagata T, et al. Effect of ambulatory oxygen on exertional dyspnea in IPF patients without resting hypoxemia. Respiratory medicine. 2013;107(8):1241-6.

34. American Thoracic Society. Idiopathic pulmonary fibrosis: diagnosis and treatment. International consensus statement. American Thoracic Society (ATS), and the European Respiratory Society (ERS). American Journal of Respiratory \& Critical Care Medicine. 2000;161(2 Pt 1):646-64. 35. 2008 National survey of idiopathic interstitial pneumonia in Korea. Scientific Committee of the Korean Academy of Tuberculosis and Respiratory Diseases. [Korean]. Tuberculosis and Respiratory Diseases. 2009;66 (2):141-51.

36. Key AL, Holt K, Hamilton A, Smith JA, Earis JE. Objective cough frequency in idiopathic pulmonary fibrosis. Cough. 2010;6(1):4.

37. Van Manen M, Birring S, Vancheri C, Vindigni V, Wapenaar M, Cottin V, et al. Cough measurements in patients with idiopathic pulmonary fibrosis (IPF). C43 IF YOU'VE GOT TROUBLE: CHRONIC COUGH: Am Thoracic Soc; 2015. p. A4422-A.

38. Morice AH, McGarvey L, Pavord I. Recommendations for the management of cough in adults. Thorax. 2006;61 Suppl 1:11-24.

39. Bradaia F, Lazor R, Khouatra C, Poissonnier L, Cottin V, Cordier JF. Urinary incontinence due to chronic cough in interstitial lung disease. [French]. Revue des Maladies Respiratoires. 2009;26 (5):499-504.

40. Irwin RS. Chronic cough due to gastroesophageal reflux disease: ACCP evidence-based clinical practice guidelines. Chest. 2006;129(1 Suppl):80S-94S.

41. Ours TM, Kavuru MS, Schilz RJ, Richter JE. A prospective evaluation of esophageal testing and a double-blind, randomized study of omeprazole in a diagnostic and therapeutic algorithm for chronic cough. Am J Gastroenterol. 1999;94(11):3131-8. 
42. Kiljander TO, Salomaa ER, Hietanen EK, Terho EO. Chronic cough and gastro-oesophageal reflux: a double-blind placebo-controlled study with omeprazole. European Respiratory Journal. 2000;16(4):633-8.

43. Ing AJ, Ngu MC, Breslin AB. A randomised double-blind placebo controlled crossover study of ranitidine in patients with chronic persistent cough associated with gastro-oesophageal reflux. . American Review Respiratory Diseases. 1992;145:A11.

44. Xue $\mathrm{S}$, Katz PO, Banerjee $\mathrm{P}$, Tutuian R, Castell DO. Bedtime $\mathrm{H} 2$ blockers improve nocturnal gastric acid control in GERD patients on proton pump inhibitors. Aliment Pharmacol Ther. 2001;15(9):1351-6.

45. Poe RH, Kallay MC. Chronic cough and gastroesophageal reflux disease: experience with specific therapy for diagnosis and treatment. Chest. 2003;123(3):679-84.

46. van Manen MJ, Birring SS, Vancheri C, Cottin V, Renzoni EA, Russell A-M, et al. Cough in idiopathic pulmonary fibrosis. European Respiratory Review. 2016;25(141):278-86.

47. Horton MR, Santopietro V, Mathew L, Horton KM, Polito AJ, Liu MC, et al. Thalidomide for the treatment of cough in idiopathic pulmonary fibrosis: a randomized trial. Ann Intern Med. 2012;157(6):398-406.

48. Ryan NM, Birring SS, Gibson PG. Gabapentin for refractory chronic cough: a randomised, double-blind, placebo-controlled trial. Lancet. 2012;380(9853):1583-9.

49. Lindell KO, Kavalieratos D, Gibson KF, Tycon L, Rosenzweig M. The palliative care needs of patients with idiopathic pulmonary fibrosis: A qualitative study of patients and family caregivers. Heart \& Lung: The Journal of Acute and Critical Care. 2017;46(1):24-9.

50. Overgaard D, Kaldan G, Marsaa K, Nielsen TL, Shaker SB, Egerod I. The lived experience with idiopathic pulmonary fibrosis: a qualitative study. European Respiratory Journal. 2016:ERJ-015662015.

51. Lindell KO, Liang Z, Hoffman LA, Rosenzweig MQ, Saul MI, Pilewski JM, et al. Palliative care and location of death in decedents with idiopathic pulmonary fibrosis. CHEST Journal. 2015;147(2):423-9.

52. Bajwah S, Ross JR, Wells AU, Mohammed K, Oyebode C, Birring SS, et al. Palliative care for patients with advanced fibrotic lung disease: a randomised controlled phase II and feasibility trial of a community case conference intervention. Thorax. 2015;70(9):830-9.

53. Sampson C, Gill BH, Harrison NK, Nelson A, Byrne A. The care needs of patients with idiopathic pulmonary fibrosis and their carers (CaNoPy): results of a qualitative study. BMC pulmonary medicine. 2015;15(1):155.

54. Boland JW, Reigada C, Yorke J, Hart SP, Bajwah S, Ross J, et al. The Adaptation, Face, and Content Validation of a Needs Assessment Tool: Progressive Disease for People with Interstitial Lung Disease. Journal of palliative medicine. 2016;19(5):549-55.

55. Reigada C, Papadopoulos A, Boland J, Yorke J, Ross J, Currow DC, Bajwah S, Grande G, Wells A, Johnson MJ. Implementation of the Needs Assessment Tool for Interstitial Lung Disease Patients (NAT:ILD): Facilitators and Barriers. Thorax 2017 online first http://dx.doi.org/10.1136/thoraxinl2016-209768

56. Bajwah S, Koffman J, Higginson IJ, Ross JR, Wells AU, Birring SS, et al. 'I wish I knew more ...' the end-of-life planning and information needs for end-stage fibrotic interstitial lung disease: views of patients, carers and health professionals. BMJ Support Palliat Care. 2013;3(1):84-90.

57. Russell A-M, Ripamonti E, Vancheri C. Qualitative European survey of patients with idiopathic pulmonary fibrosis: patients' perspectives of the disease and treatment. BMC pulmonary medicine. 2016;16(1):10.

58. Borg G. Perceived exertion as an indicator of somatic stress. Scandinavian journal of rehabilitation medicine. 1970;2(2):92.

59. Aitken RC. A Growing Edge of Measurement of Feelings [Abridged] Measurement of Feelings Using Visual Analogue Scales. SAGE Publications; 1969. 
60. Yorke J, Moosavi SH, Shuldham C, Jones PW. Quantification of dyspnoea using descriptors: development and initial testing of Dyspnoea-12. Thorax. 2009:thx. 2009.118521.

61. Fletcher CM, Elmes PC, Fairbairn AS, Wood CH. Significance of respiratory symptoms and the diagnosis of chronic bronchitis in a working population. British medical journal. 1959;2(5147):257.

62. Eakin EG, Resnikoff PM, Prewitt LM, Ries AL, Kaplan RM. Validation of a new dyspnea measure: the UCSD Shortness of Breath Questionnaire. Chest. 1998;113(3):619-24.

63. Yorke J, Swigris J, Russell A-M, Moosavi SH, Kwong GNM, Longshaw M, et al. Dyspnea-12 is a valid and reliable measure of breathlessness in patients with interstitial lung disease. CHEST Journal. 2011;139(1):159-64.

64. Nishiyama O, Taniguchi $\mathrm{H}$, Kondoh $\mathrm{Y}$, Kimura T, Kato K, Kataoka K, et al. A simple assessment of dyspnoea as a prognostic indicator in idiopathic pulmonary fibrosis. European Respiratory Journal. 2010;36(5):1067-72.

65. Swigris JJ, Streiner DL, Brown KK, Belkin A, Green KE, Wamboldt FS, et al. Assessing exertional dyspnea in patients with idiopathic pulmonary fibrosis. Respiratory medicine. 2014;108(1):181-8.

66. Swigris JJ, Han M, Vij R, Noth I, Eisenstein EL, Anstrom KJ, et al. The UCSD shortness of breath questionnaire has longitudinal construct validity in idiopathic pulmonary fibrosis. Respiratory medicine. 2012;106(10):1447-55.

67. Birring S, Prudon B, Carr A, Singh S, Morgan M, Pavord I. Development of a symptom specific health status measure for patients with chronic cough: Leicester Cough Questionnaire (LCQ). Thorax. 2003;58(4):339-43.

68. Lechtzin N, Hilliard ME, Horton MR. Validation of the Cough Quality-of-Life Questionnaire in patients with idiopathic pulmonary fibrosis. CHEST Journal. 2013;143(6):1745-9.

69. Swigris JJ, Wilson SR, Green KE, Sprunger DB, Brown KK, Wamboldt FS. Development of the ATAQ-IPF: a tool to assess quality of life in IPF. Health and quality of life outcomes. 2010;8(1):77.

70. Yorke J, Spencer LG, Duck A, Ratcliffe S, Kwong GN, Longshaw MS, et al. Cross-Atlantic modification and validation of the A Tool to Assess Quality of Life in Idiopathic Pulmonary Fibrosis (ATAQ-IPF-CA). BMJ open respiratory research. 2014;1(1):e000024.

71. Patel AS, Siegert RJ, Brignall K, Gordon P, Steer S, Desai SR, et al. The development and validation of the King's Brief Interstitial Lung Disease (K-BILD) health status questionnaire. Thorax. 2012:thoraxjnl-2012-201581.

72. Jones PW, Quirk F, Baveystock C. The St George's respiratory questionnaire. Respiratory medicine. 1991;85:25-31.

73. Swigris J, Kuschner W, Jacobs S, Wilson S, Gould M. Health-related quality of life in patients with idiopathic pulmonary fibrosis: a systematic review. Thorax. 2005;60(7):588-94.

74. Swigris JJ, Esser D, Wilson H, Conoscenti CS, Schmidt H, Stansen W, et al. Psychometric properties of the St George's Respiratory Questionnaire in patients with idiopathic pulmonary fibrosis. European Respiratory Journal. 2017;49(1):1601788.

75. Yorke J, Jones PW, Swigris JJ. Development and validity testing of an IPF-specific version of the St George's Respiratory Questionnaire. Thorax. 2010;65(10):921-6. 